\title{
Übersicht zum Aufbau der Biobibliographien
}

\author{
Autobiogr. .... Autobiographie \\ Biogr........ Biographie \\ Nekr. . . . . . Nekrolog \\ Bibliogr. ..... Bibliographie \\ Erf.......... Erfindungen \\ H.......... Herausgeber \\ MH. ......... Mitherausgeber \\ HZ...........Herausgeber von Zeitschriften \\ MHZ. ........ Mitherausgeber von Zeitschriften \\ Ue. ........ U. Übersetzer \\ S.......... Beiträge zu Sammelwerken, Handbüchern, \\ Festschriften usw. \\ W. .........Werke (Bücher) \\ - .......... bedeutet, daß es sich um selbständig erschie- \\ nene Drucke handelt \\ ${ }^{3}$ (Bln '54) .... . Die hochgestellte kleine Ziffer beim Erschei- \\ nungsvermerk von Büchern gibt die Auflage \\ (im Beispiel die dritte) an \\ f. . . . . . . hinter einer Seitenzahl gibt dic auf diese Zahl \\ folgende an, also \\ $23 \mathrm{f} . \ldots \ldots \ldots 23-24$
}

Es folgen die wissenschaftlichen Veröffentlichungen in Zeitschriften, deren Titel alphabetisch geordnet sind.

Die im Werke verwendeten Kürzungen der Zeitschriftentitel werden im Teil 4 des Bandes VIIa gegeben. 
